\title{
CASOS DA NOVA INFLUENZA A (H1N1) OCORRIDOS NO ESTADO DO PARANÁ DURANTE A PANDEMIA DE 2009
}

\section{CASES OF NEW INFLUENZA A (H1N1) OCCURRED IN PARANA STATE DURING THE PANDEMIC OF 2009}

\author{
LENZI, Luana ${ }^{1}$; WIENS, Astrid ${ }^{1}$; TRINDADE, Ângela C. L. B. ${ }^{2}$; PONTAROLO, Roberto² \\ 1 - Alunos do Programa de Pós-Graduação em Ciências Farmacêuticas - Universidade \\ Federal do Paraná \\ 2 - Professores do Departamento de Farmácia - Universidade Federal do Paraná REc:05/2010 \\ AC:06/2010
}

\begin{abstract}
RESUMO:
Durante o ano de 2009, o mundo foi surpreendido com a eclosão de uma pandemia por uma nova variante do vírus da Influenza A (H1N1). O Estado do Paraná, graças ao seu clima, posição geográfica e trânsito de pessoas, apresentou um elevado número de casos da infecção. Utilizando dados coletados a partir dos formulários de notificação da doença, foi possível realizar este estudo retrospectivo, avaliando a relação destes, com as medidas sanitárias adotadas para contenção e manejo do evento pandêmico. Os resultados mostraram que a realização de campanhas de informação, a adoção de medidas de contenção da população e o uso do medicamento oseltamivir foram essenciais para a prevenção e o controle desta pandemia.
\end{abstract}

Palavras-chave: Influenza A (H1N1), Pandemia, Oseltamivir.

\begin{abstract}
:
During 2009, the world was surprised by the outbreak of a pandemic with a new variant of influenza virus $A(\mathrm{H} 1 \mathrm{~N} 1)$. The State of Parana, thanks to its climate, geographical position and movement of people, showed a high number of cases of infection. Using data collected from the notification forms of the disease, it was possible to perform this retrospective study, evaluating their relationship with the health measures taken to contain and manage the pandemic event. The results showed that the implementation of information campaigns, the adoption of measures to contain the population and the use of the oseltamivir was essential to prevent and control this pandemic.
\end{abstract}

Keywords: Influenza A (H1N1), Pandemic, Oseltamivir.

\section{INTRODUÇÃO}

Segundo previsões estatísticas da Organização Mundial da Saúde (OMS), uma nova pandemia era esperada no transcurso dos últimos 10 anos [1]. Devido à ocorrência de alguns casos de influenza de origem aviária em diversas partes do mundo, desde o ano de 2006 havia uma notável preocupação mundial quanto ao possível surgimento de uma pandemia, causada pelo vírus Influenza A (H5N1) [2]. Entretanto, desde o final do mês de março de 2009 a preocupação voltou-se para a súbita eclosão de uma epidemia de enfermidade respiratória febril de rápida disseminação, 
cujo agente etiológico foi identificado como um vírus influenza $\mathrm{A}(\mathrm{H} 1 \mathrm{~N} 1)[3,4]$.

Devido ao grande número de indivíduos afetados durante uma pandemia os surtos de gripe são considerados problemas de saúde pública, por apresentarem impacto econômico proveniente do aumento da demanda assistencial com o conseqüente aumento de custos econômicos, tanto diretos (consultas médicas nos centros de atenção primária, hospitalizações e custos do tratamento), quanto indiretos (afastamento do trabalho e custos atribuídos ao cuidador da pessoa enferma). [5].

O objetivo deste trabalho foi avaliar a ocorrência dos casos da Influenza A (H1N1) no Estado do Paraná e o efeito alcançado com as medidas sanitárias de contenção e prevenção adotadas durante a pandemia, a fim de verificar a efetividade e a viabilidade dessas estratégias para utilização em possíveis situações futuras. Os resultados poderão contribuir para a compreensão de estratégias para a vigilância, a prevenção e o controle de doenças infecciosas.

\section{METODOLOGIA}

Este é um estudo documental e retrospectivo. Foram utilizados dados dos pacientes do Estado do Paraná que tiveram o diagnóstico positivo para Influenza A (H1N1), durante o ano de 2009, obtidos a partir dos formulários de notificação da doença coletados na Secretaria de Estado da Saúde do Paraná - SESA. Os critérios estabelecidos para a inclusão dos pacientes foram a confirmação da doença por exame laboratorial realizado por técnica de RT-PCR e o resultado etiológico positivo para o vírus Influenza A(H1N1), cepa pandêmica. Foram avaliados os registros referentes as datas do início dos sintomas e as datas dos óbitos. Os resultados foram obtidos por meio da construção de histogramas, utilizando o programa SPSS 17.0, e pela comparação das medidas adotadas pelas autoridades de saúde do Estado do Paraná em cada momento respectivo do evento pandêmico. Este Projeto foi aprovado pelo Comitê de Ética em Pesquisa do Setor de Ciências da Saúde da Universidade Federal do Paraná, sob o numero de registro 938.063.10.06 e CAAE: 0038.0.091.000-10.

\section{RESULTADOS E DISCUSSÃO}

Após o início da pandemia no México, em março de 2009, a ocorrência dos casos da Nova Influenza A (H1N1) no Estado do Paraná ao longo do ano são representados na figura 1. A figura ilustra um histograma com o registro ininterrupto dos casos ocorridos desde a data de primeiro de junho, até a data de 31 de dezembro do ano de 2009. O registro do primeiro caso confirmado laboratorialmente no estado do Paraná ocorreu no dia quatro de junho de 2009. A maior freqüência no registro dos casos ocorreu entre o final de julho e início de agosto, com o registro máximo de 178 casos no dia 3 de agosto. Este período coincide com a sazonalidade da doença no Estado em decorrência do período de inverno, fato este, que pode ter contribuído para o aumento do número de casos da doença. 
FIGURA 1 - HISTOGRAMA DOS CASOS DE INFLUENZAA (H1N1) NO ESTADO DO PARANÁ DURANTE O ANO DE 2009.

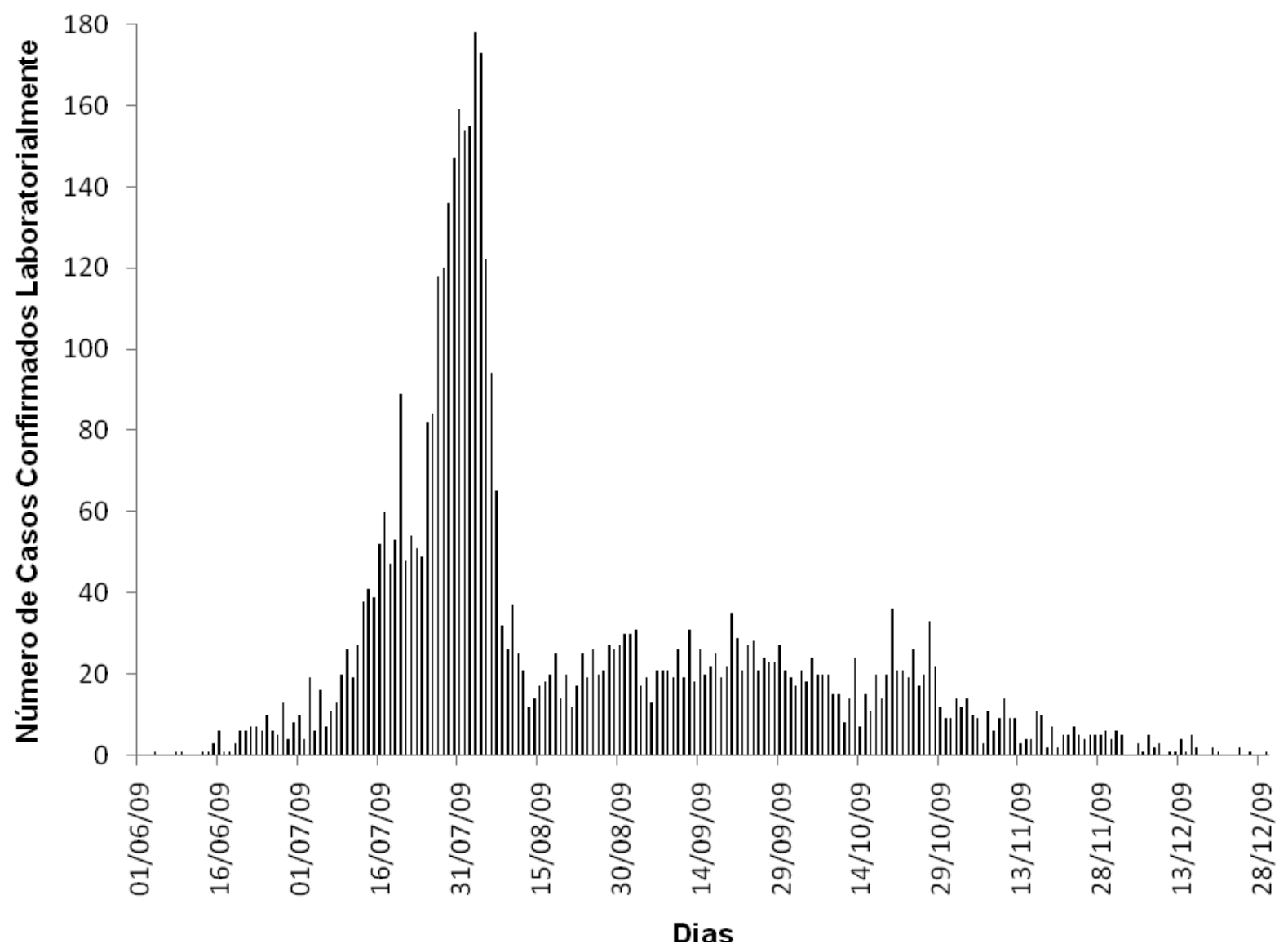

A população estava em pânico com o imenso número de casos que eram oficialmente (ou extra oficialmente) divulgados, principalmente por não ser até então conhecida a mortalidade por esta nova variante viral. Além disso, graças à divulgação das semelhanças genéticas desta nova cepa viral com a responsável pela gripe espanhola ocorrida em 1918, a disseminação do medo foi ainda maior.

A diminuição significativa do número de casos a partir da segunda semana do mês de agosto é um reflexo das medidas de contenção que foram adotadas em todo o Estado do Paraná. Visando o controle da situação e na tentativa de proteger a população contra a infecção, as autoridades de saúde locais intensificaram as campanhas de informação e educação sobre como se proteger desta infecção e sobre quando e onde buscar auxílio médico. As campanhas foram divulgadas por cartazes, mensagens em ônibus, programas de televisão, rádio e outros. Dentre as informações divulgadas por essas campanhas, estavam as orientações sobre o uso correto de álcool gel a 70\%, a lavagem recorrente das mãos com água e sabão, o uso de máscaras de proteção e a importância de manter os ambientes arejados e evitar aglomerações. Além disso, orientava sobre os principais sinais e sintomas indicativos da infecção e para que o indivíduo procurasse auxílio médico o mais breve possível ao suspeitar dos primeiros sintomas. Outras medidas mais severas de contenção que começaram a ser tomadas pelas autoridades de saúde, foram a suspensão das aulas e o cancelamento de eventos que acarretassem em aglomeração de pessoas. 
Essas estratégias foram adotadas devido à principal forma de transmissão do vírus Influenza, que ocorre pela via respiratória, por meio do contato direto com gotículas de aerossóis contaminadas com o vírus, provenientes da tosse, espirro ou fala de um indivíduo doente, lembrando que a transmissão da doença pode ocorrer antes mesmo do aparecimento dos sintomas. Outra forma de contágio é a transmissão indireta, por meio de fômites contaminados com o vírus, realizando o contato deste com as mucosas nasal, oral ou conjuntiva.

Assim, por tratar-se de uma doença de transmissão principalmente respiratória, conhecer as formas de prevenção da doença são de extrema importância para o controle do número de casos. Os resultados observados após o aumento das campanhas educativas contribuem com a conclusão de que instruir o indivíduo ao seu autocuidado é uma ferramenta importante na prevenção e controle de uma pandemia.

A figura 2 ilustra os casos que evoluíram ao desfecho óbito. Pode-se observar que o maior número de óbitos coincide com o período de maior registro de casos, ou seja, entre os meses de julho e agosto. O primeiro registro ocorreu no dia primeiro de julho e o maior registro diário de óbitos (12) ocorreu no dia cinco de agosto de 2009. Além disso, o aumento da distribuição do medicamento oseltamivir em meados do mês de agosto pode ter contribuído para a diminuição do número de óbitos pela infecção.

FIGURA 2 - HISTOGRAMA DOS ÓBITOS PELA NOVA INFLUENZA A (H1N1) REGISTRADOS NO ESTADO DO PARANÁ DURANTE A PANDEMIA DE 2009

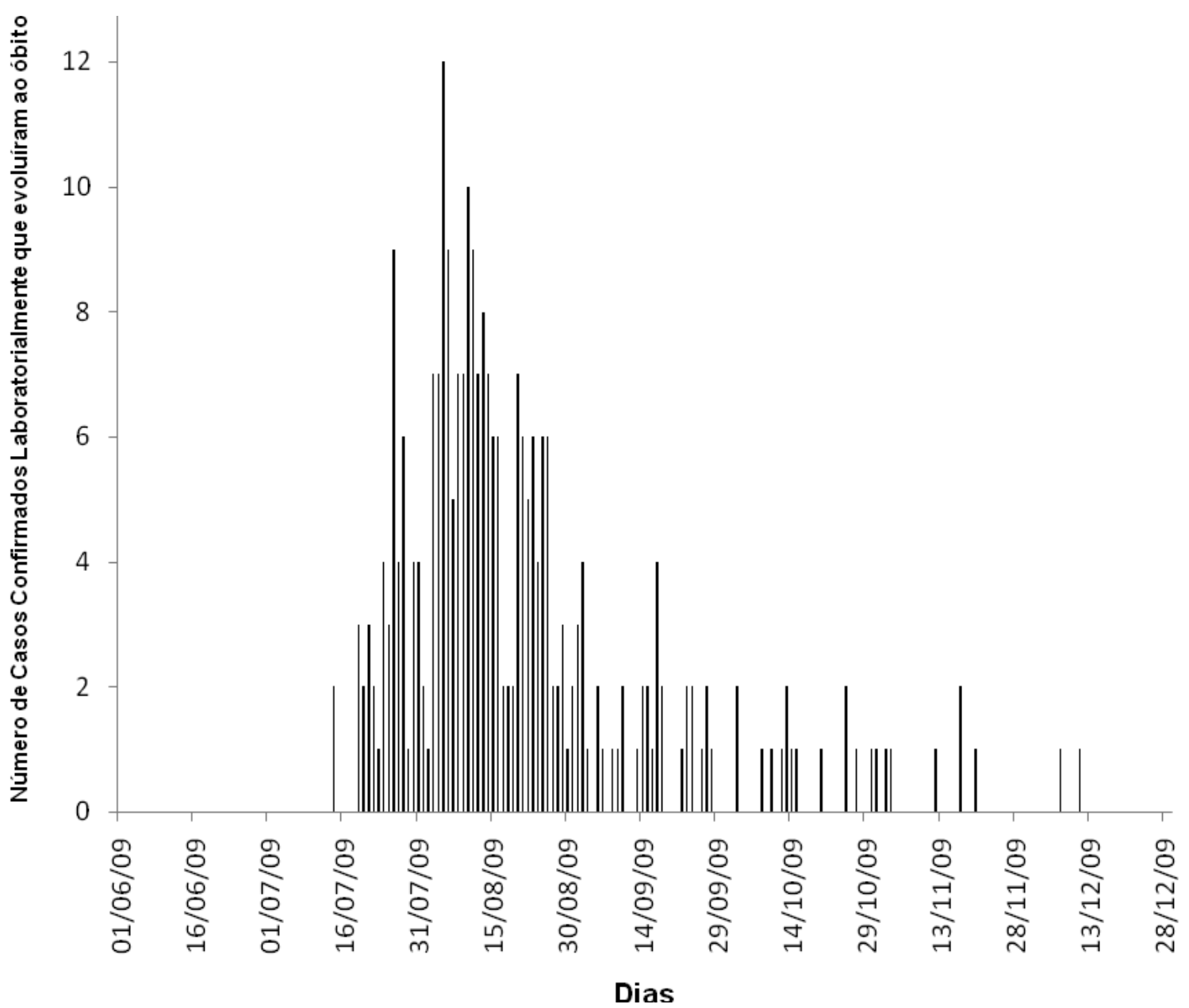


O número de óbitos só não foi maior, graças ao preparo das autoridades locais para o enfrentamento da situação, tanto por meio da adoção de medidas educativas e sanitárias, quanto pelo manejo dos casos junto ao sistema de saúde do Estado, por intermédio da distribuição efetiva do oseltamivir aos pacientes com sintomas indicativos da infecção.

\section{CONCLUSÃO}

A maior característica desta pandemia foi a sua rápida disseminação por todo o mundo, e não a sua severidade, como era esperado dada a sua semelhança com o tipo viral causador da Gripe Espanhola.

Os resultados obtidos neste estudo confirmam que a adoção de medidas de senso comum de prevenção, como frequentes lavagens das mãos, redução do contato íntimo e pessoal, suspensão de situações que gerem aglomeração, e o fornecimento de orientações sobre a doença são ferramentas de extrema importância no controle efetivo de uma pandemia de veiculação respiratória.

\section{REFERÊNCIAS}

Alija FJR: La gripe. Revista Médica de Homeopatía; 2(3): p. 127-136.

Chang LY, Shih SR, Shao PL, Huang DT, Huang LM: Novel swine-origin influenza virus A(H1N1): the first pandemic of the 21st century. J Formos Med Assoc 2009; 108(7): p. 526-32.

Carmo E, Oliveira W, Risco de uma pandemia de influenza pelo vírus A (H1N1), Secretaria De Vigilância Em Saúde Mds, Editor. 2009, Cad. Saúde Pública. p. 1192-1193.

Forleo-Neto E, Halker E, Santos VJ, Paiva TM, Toniolo-Neto J: [Influenza]. Rev Soc Bras Med Trop 2003; 36(2): p. 267-74.

Badia Llach X, Roset Gamisans M, Frances Tudel JM, Alvarez Sanz C, Rubio Terres C: [Study of flu costs]. Aten Primaria 2006; 38(5): p. 260-7. 